\title{
Rethinking research processes to strengthen co-production in low and middle income countries
}

\author{
Co-production needs to become an integral part of the training and funding of researchers to \\ ensure research meets everyone's needs, argue David Beran and colleagues
}

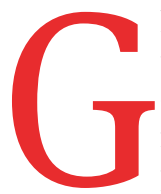

lobal health research needs to include a greater diversity of stakeholders within the research process. Involving people who are not academics in the co-production of research has many potential benefits: generation of a wider range of ideas; including the needs of people directly affected by the research; inclusion of broader sets of skills and views, values, and epistemologies in designing projects; allowing dialogue, participative decision making processes throughout the development and delivery of research; ensuring uptake of research results; increasing legitimacy and acceptance; and assuring sustainability. ${ }^{1-5}$

However, co-production has its own challenges. ${ }^{167}$ For example, finding practical ways to collaborate with stakeholders outside academia to prepare grant applications and proposals is a substantial challenge. The "negative" costs of co-production are described as the costs of actually doing co-production; personal and professional costs to the researcher; costs to participants; and costs to projects in general of this appraoch. ${ }^{7}$ Successful co-production requires the corresponding skills and appropriate tools and resources to include a wide variety of stakeholders. This in turn challenges current training, career progression pathways, and funding processes for researchers. Research

\section{REY MESSAGES}

- Researchers are being asked to coproduce research with relevant stakeholders, without being given the appropriate tools and resources to do this effectively

- The research agenda and its development and implementation should have more active involvement from lay participants, healthcare providers, policy makers, and other stakeholders

- Training and funding processes need to be rethought and adapted to facilitate co-production more routinely funders are key to many of these and include government research councils or foundations, independent foundations, and government development agencies, particularly in low and middle income countries (LMICs). Stakeholders include people with a given health problem, community members, healthcare providers, civil society organisations, and policy makers.

Changes are required in global health research to ensure that co-production is strengthened and help overcome the challenges that researchers face in implementing it. The first obstacle is the pressing challenges in many LMIC settings, ranging from high disease burden to fragmented health systems, poverty, and inequities. These are complex and interconnected problems. ${ }^{8}$ Secondly, this complexity necessitates interdisciplinary, multidisciplinary, and transdisciplinary approaches. ${ }^{9}$ This requires the recognition by researchers and funders that contributions from a broad spectrum of relevant experts and stakeholders is crucial for co-production ${ }^{910}$ and that they need to be included in the research process from the beginning. Finally, researchers need to work with existing partners, or identify possible partners, in countries and start adapting or developing new ideas and translating these into a comprehensive research proposal. This process also raises the issue of unequal power relations between different parties involved, in terms of the value placed on their ideas and knowledge. Overcoming these three challenges takes time and requires building trust with academic and non-academic partners in the funding application as well as multiple stakeholders beyond the research proposal. ${ }^{11}$ In addition, training, career progression, institutional decisions and investment, and funding processes need to be rethought.

\section{Training and communication are essential}

Tackling complex issues in LMICs and engaging in successful co-production requires specific training for researchers in global health theory, policy, and practice, ${ }^{57}$ as well as increased knowledge and awareness of global health issues by funders and reviewers. Cross-cultural awareness and communication skills are also needed to enable effective communication between partners from different cultural and geographical settings, as well as between researchers and stakeholders with different backgrounds from the same country. For example, as part of the Swiss Programme for Research on Global Issues for Development (r4d programme), the Swiss National Science Foundation organised training on cultural communication, influencing policy makers, etc for researchers it funded. ${ }^{12}$ Such training, however, should be part of the foundation of a researcher's skills and not delivered on an ad hoc basis.

Researchers also need training to provide them with the tools and skills for advocacy. In parallel, the role of academic researchers in shaping policy also needs to be defined in the context of co-production. The link between research and advocacy can be straightforward when the evidence generated is directly linked to an issue that is of interest to policy makers. ${ }^{13}$ However, simply providing and promoting results to policy makers is different from researchers and other stakeholders advocating for the interests of communities.

\section{Time, resources, and "cost"}

Co-production requires more time and investment by researchers than traditional models of research, ${ }^{114}$ potentially taking time away from other academic activities. Beyond the time needed to actually implement co-production in the development and delivery of research, there is the need to invest in developing relationships, identifying ways of working together, conducting formative research, building a common language, and securing and sharing gains. These efforts are not adequately acknowledged by institutions and funders. The outputs from co-production do not match the metrics commonly used to assess the track record of academics-namely, high impact factor publications-as they may not be a 
standard randomised trial or suitable for peer reviewed publications. ${ }^{8}$

Involving stakeholders in co-production also has financial and non-financial costs for researchers, such as the time and "emotional" costs of explaining that the research will address only one of the many needs stakeholders might have. ${ }^{7}$ In many LMICs, high staff turnover among collaborating organisations makes it harder to maintain links and relationships.

In Peru, a co-creation process to develop an intervention to improve the diagnosis and management of chronic diseases (diabetes, hypertension, and neurocysticercosis), highlighted divergent views between different stakeholders and the community raised issues that were beyond the "intended" scope of the project. ${ }^{1}$ For example, the community priority was improving water and sanitation, whereas the focus of the project was on strengthening the health system. The trust developed through the project and the time invested in the interactions with stakeholders and the community resolved these differences and established common understanding.

Co-production requires having the appropriate skills and the resources to be able to focus energy on these activities, which are usually beyond the scope and duration of time-bounded research projects. These costs need to be accounted for and built into budgets and rules for funding to facilitate the reality of co-produced research in LMICs.

\section{Platforms for exchange}

Investment in creating platforms to enable equal exchanges facilitates relationships between researchers and stakeholders. ${ }^{69}$ For example, the James Lind Alliance brings together people with specific health needs, carers, and clinicians to identify and prioritise research gaps with the aim of improving care. ${ }^{10}$ Other organisations have institutionalised this multistakeholder approach-for example, the UK's National Institute for Health and Clinical Excellence, the faculty of medicine at the University of Montreal, and the Welsh ALPHA (Advice Leading to Public Health Advancement) group, where people representing certain interest groups or with a certain disease sit on decision making panels. ${ }^{15-17}$ Such platforms ensure that people with specific health problems can present their expertise and perspective ${ }^{2}$ rather than academics or funders setting priorities, and enables research to reflect societal concerns. ${ }^{4}$ These platforms should operate as an interface and allow for exchange and dissemination to occur between science, social organisations, and policy makers.

Platforms can also empower stakeholders and foster the development of relationships and partnerships that facilitate power sharing and enable co-production. ${ }^{18}$ The example from Peru shows how a co-production approach enabled stakeholders to transition from key informants during the formative research, to active partners in co-creating solutions, and finally towards direct or indirect involvement in implementing the intervention they helped produce. ${ }^{1}$

Strong and equitable partnerships with buy-in and engagement of all partners, as well as funders, are the foundations of an effective co-production process in global health research. Many guidelines exist to help develop and foster partnerships, such as the 11 principles outlined by the Swiss Commission for Research Partnerships with Developing Countries. ${ }^{19}$ In addition, tools such as the Research Fairness Initiative ensure due diligence in establishing partnerships. ${ }^{20}$ Furthermore, co-production itself can be seen as a tool for empowerment and partnerships, ${ }^{5}$ with funders having a role in promoting equitable partnerships. ${ }^{21}$

\section{Increasing evidence and uptake}

Some validated approaches and guidelines to help direct and apply co-production processes already exist. ${ }^{16}$ The UK's National Institute for Health Research ${ }^{3}$ provides five principles: "Sharing power, including all perspectives and skills, respecting and valuing the knowledge of all those working together on the research, reciprocity, and building and maintaining relationships." 2221 Critics of co-production argue there is an absence of evidence for implementing co-production and that most research focuses on promoting the wider use of co-production or reflects a theoretical discourse that is not easily translated into actions. More evidence about the effectiveness of co-production compared with the usual academic approaches is lacking. ${ }^{101823}$ However, this discussion leads to a vicious cycle: if co-production is not considered "scientific enough" through a lack of evidence for funders and journals to support it, then the chances of funding and creating evidence diminish further. From a development perspective, co-production is seen as an essential tool in achieving the sustainable development goals, ${ }^{23}$ where research is needed to address a wide range of intermingled complex challenges. How- ever, many development agencies' remits have not included funding or support to research and academic institutions for partnering related activities.

Funders have an influential role in shaping the research agenda by making certain elements an essential part of their funding process-for example, public engagement is now part and parcel of research. ${ }^{24}$ With development funders increasingly funding research in LMICs, researchers will have to meet new metrics and requirements. ${ }^{25}$ Researchers will need to continuously adapt their approaches and CVs to meet these changes in an evolving funding environment. Therefore, funders should encourage the integration of co-production as an essential component of research to ensure that research has a larger impact on society, improving the health and wellbeing of those being "researched."

Although the benefits of co-production outweigh the challenges, changes are needed in the conceptualisation of co-production in research in LMICs for this to become part and parcel of research with adequate funding (table 1). Our experience suggests that one important change is to refer to people with health conditions as partners in co-production not patients. Describing people as "patients" often narrows their contribution to a specific disease, while ignoring complexity in health outcomes and underplays the holistic views they bring as individuals.

Researchers also need protected time and resources to truly work in a co-productive way with their partners and stakeholders, both at the stage of developing a proposal and in the conduct of the research. Innovations such as engagement platforms need to be created to enable this knowledge to be integrated from the outset of the research process. Co-produced research tends not to fit traditional calls for funding around vertical disease or specific themes or generate standard outputs, including academic publications, since it tends to be more horizontal in nature, scope, and engagement. ${ }^{826}$ Metrics to evaluate researchers and assess the successful implementation of co-production beyond high impact publications should be developed.

More radical rethinking would consider funding partnerships rather than projects. The concept of co-production might be better integrated beyond the requirements of a single study, instead being built and sustained over a range of activities over time under the umbrella of an organisational partnership. Rather than 


\begin{tabular}{|c|c|c|c|}
\hline & Training & Resources & Engagement \\
\hline \multirow[t]{5}{*}{$\begin{array}{l}\text { Researchers and } \\
\text { academic institutions }\end{array}$} & $\begin{array}{l}\text { Develop training programmes adapted } \\
\text { to co-production methods }\end{array}$ & \multirow[t]{2}{*}{$\begin{array}{l}\text { Provide resources and infrastructure for the } \\
\text { development of institutional partnerships }\end{array}$} & \multirow{5}{*}{$\begin{array}{l}\text { Institutionalise engagement mechanisms } \\
\text { with stakeholders, including policy makers } \\
\text { and social organisations }\end{array}$} \\
\hline & \multirow{3}{*}{$\begin{array}{l}\text { Foster multidisciplinary, interdisciplinary, } \\
\text { and transdisciplinary training }\end{array}$} & & \\
\hline & & $\begin{array}{l}\text { Develop guidelines and methods } \\
\text { for co-production }\end{array}$ & \\
\hline & & \multirow{2}{*}{$\begin{array}{l}\text { Provide key frameworks for the establishment of } \\
\text { equitable partnerships }\end{array}$} & \\
\hline & $\begin{array}{l}\text { Provide cross-cultural, communication } \\
\text { and advocacy training }\end{array}$ & & \\
\hline \multirow[t]{5}{*}{ Funders } & \multirow[t]{5}{*}{$\begin{array}{l}\text { Support training programmes and invite } \\
\text { non-academic participants to participate }\end{array}$} & \multirow{2}{*}{$\begin{array}{l}\text { Ensure adequate time is available to include } \\
\text { co-production throughout the development } \\
\text { and conduct of research projects }\end{array}$} & $\begin{array}{l}\text { Include lay people within decision } \\
\text { making processes }\end{array}$ \\
\hline & & & \multirow{4}{*}{$\begin{array}{l}\text { Fund engagement mechanisms and platforms } \\
\text { with policy makers and social organisations }\end{array}$} \\
\hline & & Adequately fund projects in line with local needs & \\
\hline & & $\begin{array}{l}\text { Support the development of partnerships beyond } \\
\text { (and in addition to) one-off projects }\end{array}$ & \\
\hline & & $\begin{array}{l}\text { Support the development of new approaches and } \\
\text { methods in co-production }\end{array}$ & \\
\hline
\end{tabular}

expecting one project to fit the bill of a "perfect" co-production project, resources should be put into fostering a series of meaningful interactions with key partners from high income countries as well as LMICs, within and beyond academia. This would nurture co-production efforts in the spirit of equitable partnerships. Academic institutions globally will also need to incorporate a long term view towards meaningful partnerships, leading to institutional incentives and investment, to break the problem of funders continuously setting the agenda, turning into short lived partnerships.

The current challenge for researchers is knowing whose needs they should prioritise: the communities in which they are working, policy makers in the country where they are working, policy makers in the country funding the research, or the funder? Arguably, the model we operate is "who pays the piper calls the tune." Change is required for researchers, funders, and stakeholders to jointly decide what tune will be played, and also the instrument(s) that are used.

We thank Claudia Rutte, programme coordinator of the Swiss Programme for Research on Global Issues for Development (r4d programme) at the Swiss National Science Foundation, for her comments.

Contributors and sources: DB is the guarantor. This article was commissioned following discussions between DB and JJM with the Alliance for Health Systems and Policy Research on the topic of coproduction. DB, MAP, JJ, MLP, AL, CR, and JJM are all academics involved in global research on health or the environment. BJH works at the Wellcome Trust, an independent research foundation with a large global health portfolio, and MTB works at the UK Collaborative on Development Research, a collaboration of UK funders of international development research. Both their contributions represent their personal views. EP has experience in interactions with policy makers within Switzerland and at a global and national level from the viewpoint of a government donor. MCB brings a unique perspective as someone living with a health condition and who has had an advisory role within a research project. This article was prepared through the sharing of experiences from each co-author as well as existing literature.

Competing interests: We have read and understood BMJ policy on declaration of interests and have no relevant interests to declare.

Contributors and sources:DB, MAP, MLP, and JJM all worked on the COHESION Project funded by the Swiss National Science Foundation and the Swiss Development Cooperation under the $\mathrm{r} 4 \mathrm{~d}$ programme. $M L P$ is also funded by the Swiss excellence government scholarship. JJ and AL conducted a synthesis project within the Swiss r4d programme on the "utilization of research knowledge."

Patient and public involvement: MCB represents the voice of people with a health condition. MCB has contributed to a research project that DB and MLP are involved with, as an advisor as well as in various discussions relevant to this submission. She provided key elements needed to ensure that the perspective of non-academics was included in this article.

Provenance and peer review: Commissioned; externally peer reviewed.

This article is part of a series produced in conjunction with the WHO and the Alliance for Health Policy Systems and Research with funding from the Doris Duke Charitable Foundation. The BMJ peer reviewed, edited, and made the decision to publish.

David Beran, lecturer

Maria Amalia Pesantes, researcher ${ }^{2}$

Maria Claudia Berghusen, diabetes advocate ${ }^{3}$ Branwen J Hennig, senior portfolio lead ${ }^{4}$ Johanna Jacobi, senior research scientist ${ }^{5,6}$ Maria Lazo-Porras, PhD student ${ }^{1,2}$

Aymara Llanque, postdoctoral research associate ${ }^{7}$ Enrichetta Placella, deputy head ${ }^{8}$

Carmenza Robledo-Abad, associate senior researcher ${ }^{9}$

Marta Tufet Bayona, executive director ${ }^{10}$

J Jaime Miranda, professor ${ }^{2,11}$

${ }^{1}$ Division of Tropical and Humanitarian Medicine, University of Geneva and Geneva University Hospitals, Geneva, Switzerland

${ }^{2}$ CRONICAS Centre of Excellence in Chronic Diseases, Universidad Peruana Cayetano Heredia, Lima, Peru
${ }^{3}$ Lima, Peru

${ }^{4}$ Wellcome Trust, London, UK

${ }^{5}$ Centre for Development and Environment, University of Bern, Switzerland

${ }^{6}$ Institute of Geography, University of Bern, Switzerland

'University of Bern Switzerland Centre for Development and Environment, La Paz, Bolivia ${ }^{8}$ Global Health Program, Swiss Agency for Development and Cooperation, Bern, Switzerland ${ }^{9}$ Department of Environmental Systems Science, ETH Zurich, Zurich, Switzerland

${ }^{10}$ UK Collaborative on Development Research, London, UK

${ }^{11}$ George Institute for Global Health, University of New South Wales, Sydney, Australia

Correspondence to: D Beran david.beran@unige.ch

This is an Open Access article distributed under the terms of the Creative Commons Attribution IGO License (https://creativecommons.org/licenses/ by-nc/3.0/igo/), which permits use, distribution, and reproduction for non-commercial purposes in any medium, provided the original work is properly cited.

\section{Check for updates}

1 Lazo-Porras M, Perez-Leon S, Cardenas MK, et al. Lessons learned about co-creation: developing a complex intervention in rural Peru. Glob Health Action 2020;13:1754016. doi:10.1080/16549716 .2020 .1754016

2 Litva A, Coast J, Donovan J, et al. 'The public is too subjective': public involvement at different levels of health-care decision. Soc Sci Med 2002;54:182537. doi:10.1016/S0277-9536(01)00151-4

3 Hickey G, Brearley S, Coldham T, et al. Guidance on co-producing a research project. INVOLVE, 2018.

4 Ciarli T, Rafols I. The relation between research priorities and societal demands: the case of rice. Res Policy 2019;48:949-67. doi:10.1016/j. respol.2018.10.027

5 Needham C, Carr S. Co-production: an emerging evidence base for adult social care transformation. Social Care Institute for Excellence, 2009.

6 Lambert N, Carr S. 'Outside the original remit': coproduction in UK mental health research, lessons 
from the field. Int / Ment Health Nurs 2018;27:127381. doi:10.1111/inm.12499

7 Oliver K, Kothari A, Mays N. The dark side of coproduction: do the costs outweigh the benefits for health research? Health Res Policy Syst 2019;17:33.

8 Beran D, Chappuis F, Damasceno A, et al, COHESION Project. High-quality health systems: time for a revolution in research and research funding. Lancet Glob Health 2019;7:e303-4. doi:10.1016/S2214 109X(18)30529-1

9 Jacobi J, Llanque A, Bieri S, et al. Utilization of research knowledge in sustainable development pathways: insights from a transdisciplinary research-for-development programme. Environ Sci Policy 2020;103:21-9. doi:10.1016/j. envsci.2019.10.003

10 Madden M, Morley R. Exploring the challenge of health research priority setting in partnership: reflections on the methodology used by the James Lind Alliance Pressure Ulcer Priority Setting Partnership. Res Involv Engagem 2016;2:12. doi:10.1186/s40900-016-0026-y

11 Gautier L, Sieleunou I, Kalolo A. Deconstructing the notion of "global health research partnerships" across Northern and African contexts. BMC Med Ethics 2018;19:49. doi:10.1186/s12910-0180280-7

12 Swiss National Science Foundation. Swiss programme for research on global issues for development. 2020 http://www.r4d.ch
13 Smith KE, Stewart EA. Academic advocacy in public health: disciplinary ‘duty' or political 'propaganda’?Soc Sci Med 2017;189:35-43. doi:10.1016/j.socscimed.2017.07.014

14 Lehmann U, Gilson L. Action learning for health system governance: the reward and challenge of co-production. Health Policy Plan 2015;30:957-63. doi:10.1093/heapol/czu097

15 Université de Montréal Comité de patients experts [Patient expert committee]: University of Montreal; 2020 https://medecine.umontreal.ca/faculte/ direction-collaboration-partenariat-patient/comitede-patients-experts

16 National Institute for Health and Clinical Excellence. Patient and public involvement policy. National Institute for Health and Clinical Excellence, 2013.

17 DECIPHer. Public Involvement ALPHA Cardiff: DECIPHer; 2020. https://decipher.uk.net/publichealth-improvement-research-networks-phirns/ public-involvement-alpha/

18 Mitton C, Smith N, Peacock S, Evoy B, Abelson J. Public participation in health care priority setting a scoping review. Health Policy 2009;91:219-28. doi:10.1016/j.healthpol.2009.01.005

19 KFPE. A guide for transboundary research partnerships. Swiss Commission for Research Partnerships with Developing Countries, Swiss Academy of Sciences, 2012

20 COHRED. Research fairness initiative. Council for Health Research for Development, 2020. http://www. cohred.org
21 Tembo D, Hickey D, Chandler G, et al. Effective engagement and involvement with community stakeholders in the co-production of global health research. BMJ 2021:372:n178 doi:10.1136/bmj. $\mathrm{n} 178$

22 Dodson J. Building partnerships of equals: the role of funders in equitable and effective international development collaborations. UK Collaborative on Development Sciences, 2017.

23 Clarke D, Jones F, Harris R, Robert G, Collaborative Rehabilitation Environments in Acute Stroke (CREATE) team. What outcomes are associated with developing and implementing co-produced interventions in acute healthcare settings? A rapid evidence synthesis. BMJ Open 2017;7:e014650. doi:10.1136/bmjopen-2016-014650

24 United Nations. New innovation approaches to support the implementation of the Sustainable Development Goals. UN, 2017.

25 Russell J, Greenhalgh T, Taylor M. Patient and public involvement in NIHR research 2006-2019: policy intentions, progress and themes. National Institute for Health Research, 2019.

26 Ritchie E. ODA for research \& development: too much of a good thing? Center for Global Development, 2019.https://www.cgdev.org/blog/oda-researchdevelopment-too-much-good-thing

Cite this as: $B M J$ 2021;372:m4785

http://dx.doi.org/10.1136/bmj.m4785 